\title{
Associations of life course socioeconomic position and job stress with carotid intima-media thickness. The Brazilian Longitudinal Study of Adult Health (ELSA-Brasil)
}

\section{Citation}

Camelo, Lidyane V., Luana Giatti, Dóra Chor, Rosane Härter Griep, Isabela M. Benseñor, Itamar S. Santos, Ichiro Kawachi, and Sandhi Maria Barreto. 2015. "Associations of Life Course Socioeconomic Position and Job Stress with Carotid Intima-Media Thickness. The Brazilian Longitudinal Study of Adult Health (ELSA-Brasil)." Social Science \& Medicine 141 (September): 91-99. https://doi.org/10.1016/j.socscimed.2015.07.032.

\section{Permanent link}

http://nrs.harvard.edu/urn-3:HUL.InstRepos:41288294

\section{Terms of Use}

This article was downloaded from Harvard University's DASH repository, WARNING: This file should NOT have been available for downloading from Harvard University's DASH repository.

\section{Share Your Story}

The Harvard community has made this article openly available.

Please share how this access benefits you. Submit a story.

\section{Accessibility}




\title{
Associations of life course socioeconomic position and job stress with carotid intima-media thickness. The Brazilian Longitudinal Study of Adult Health (ELSA-Brasil)
}

\author{
Lidyane V. Camelo a, b , Luana Giatti $^{\text {a, c }}{ }^{\text {, Dóra Chor }}{ }^{\text {d, }}$, Rosane Härter Griep ${ }^{\text {, }}$ \\ Isabela M. Benseñor ${ }^{\mathrm{f}}$, Itamar S. Santos ${ }^{\mathrm{g}}$, Ichiro Kawachi ${ }^{\mathrm{b}}$, Sandhi Maria Barreto ${ }^{\mathrm{a}, *}$ \\ ${ }^{a}$ Postgraduate Program in Public Health, Faculty of Medicine, Universidade Federal de Minas Gerais, Avenida Professor Alfredo Balena, 190, Belo Horizonte, \\ Minas Gerais 31930-800, Brazil \\ b Department of Social and Behavioral Sciences, Harvard School of Public Health, 677 Huntington Avenue, Boston, MA 02115, USA \\ ' School of Nutrition, Universidade Federal de Ouro Preto, Campus Universitário, Morro do Cruzeiro, 35400-000 Ouro Preto, Minas Gerais, Brazil \\ d Escola Nacional de Saúde Pública, Fundação Oswaldo Cruz, Av. Brasil, 4365, Manguinhos, 21040-360 Rio de Janeiro, Rio de Janeiro, Brazil \\ e Laboratory of Health and Environment Education, Fundação Oswaldo Cruz, Av. Brasil, 4365, Manguinhos, 21040-360 Rio de Janeiro, Rio de Janeiro, Brazil \\ ${ }^{\mathrm{f}}$ Center for Clinical and Epidemiologic Research, Hospital Universitário, Universidade de São Paulo, Avenida Professor Lineu Prestes, 2565, 30 andar, Cidade \\ Universitária, 05508-000 São Paulo, São Paulo, Brazil \\ g Internal Medicine Department, School of Medicine, Universidade de São Paulo, Avenida Doutor Arnaldo, 455, Cerqueira César, 01246-903 São Paulo, São \\ Paulo, Brazil
}

\section{A R T I C L E I N F O}

\section{Article history:}

Received 8 February 2015

Received in revised form

27 July 2015

Accepted 28 July 2015

Available online 31 July 2015

\section{Keywords:}

Life course

Health inequalities

Socioeconomic position

Atherosclerosis

IMT

Job stress

Cardiovascular disease

\begin{abstract}
A B S T R A C T
Rationale: The association between life course socioeconomic position (SEP) and subclinical atherosclerosis is not consistent across studies. Socioeconomic adversities early in life are related to an increased probability of a low occupational grade and more stressful jobs in adulthood. However, the role of job stress in explaining the life course social gradient in subclinical atherosclerosis is unknown. Objectives: To examine whether life course SEP is associated with carotid intima-media thickness (IMT) and to investigate whether this association is partially mediated by job stress.

Methods: This study used baseline data (2008-2010) for 8806 current workers from ELSA-Brasil. Maternal education, social class of first occupation and social class of current occupation were used to evaluate childhood, youth and adulthood SEP, respectively. Accumulation of risk across the life course was also evaluated. Job stress was assessed by the Swedish Demand-Control-Support Questionnaire. Directed acyclic graph and linear regression models were used.

Results: Low childhood SEP was associated with increased IMT only in women, but low youth and adulthood SEP were associated with higher IMT in both genders. The simultaneous adjustment for all SEP indicators showed that only adulthood SEP continued to be associated with IMT. However, higher IMT values were observed among men and women sequentially exposed to low SEP in more than one period of life. High-strain jobs and low job control were not associated with IMT independent of SEP.

Conclusion: Our results support a model of the cumulative effects of exposures to SEP across the life span because the highest IMT values were observed in individuals sequentially exposed to low SEP in more than one period of life. We did not find that job stress explained the association between life course SEP and IMT, suggesting that strategies to address socioeconomic inequalities in CVD should target additional steps beyond reducing job stress.
\end{abstract}

(c) 2015 Elsevier Ltd. All rights reserved.

\footnotetext{
* Corresponding author.

E-mail address: sbarreto@medicina.ufmg.br (S.M. Barreto).
}

\section{Introduction}

Socioeconomic position (SEP) is robustly inversely associated with cardiovascular disease (CVD) (Harper et al., 2011). Evidence is also accumulating for an important role of SEP in promoting early 
manifestations of subclinical atherosclerosis (Lamont et al., 2000; Rosvall et al., 2002; Lemelin et al., 2009), suggesting a possible mechanism connecting SEP and CVD. For the most part, previous studies have used only current measures of SEP, which may not provide a complete picture of the social patterning of subclinical atherosclerosis because it is known the atherosclerotic process begins even in childhood (Stary, 2000).

The few studies that have investigated the association between exposures to social adversities in childhood and subclinical atherosclerosis have been inconsistent. Lower parental SEP was associated with higher subclinical atherosclerosis in some studies (Lamont et al., 2000; Rosvall et al., 2002; Lemelin et al., 2009), but not in others (Kivimäki et al., 2005; Agha et al., 2011). In addition, some researchers found an association only among women (Rosvall et al., 2002; Lemelin et al., 2009). There is also evidence that cumulative socioeconomic disadvantage across the life course can promote subclinical atherosclerosis (Rosvall et al., 2002; Agha et al., 2011; Carson et al., 2007), but in other studies, this association was found only among men (Agha et al., 2011) or only among women (Rosvall et al., 2002).

A number of mechanisms have been put forward to account for the association between early SEP and atherosclerosis in adulthood. It is possible that low SEP in early life could promote atherosclerosis only because it leads to lower adulthood SEP. However, evidence is also accumulating for a more fundamental role of socioeconomic adversity in early life because this exposure could prompt epigenetic modifications affecting the transcription of the glucocorticoid receptor, leading to glucocorticoid resistance. This phenotype may deregulate the neuroendocrine feedback governed by the hypothalamic-pituitary-adrenal axis (HPA), leading to an elevated secretion of cortisol and inflammatory markers (Miller et al., 2011). As atherosclerosis is considered an inflammatory disease, this proinflammatory phenotype could exert an important role in the causal mechanism between early SEP and the atherosclerotic process. In fact, many observational studies have reported that childhood SEP is associated with chronic inflammation in adulthood (Camelo et al., 2014; Loucks et al., 2010).

Social adversities in early life are also associated with stressors such as crowding, growing up in poor neighborhoods, experiences of childhood trauma and abuse, and discrimination (Cohen et al., 2010). Following the theory of allostatic load (McEwen, 2012), all of these sources of stress together could also lead to long-term effects resulting in prolonged activation of the allostatic systems, which leads to physiological alterations in the nervous, endocrine and immune systems (McEwen, 2012; Danese and McEwen, 2013). All of these modifications could promote chronic diseases such as atherosclerosis or might cause proximal risk factors for atherosclerosis such as hypertension, diabetes and obesity. Moreover, chronic stress throughout life could also increase the probability that individuals will engage in health-risk behaviors (e.g., unhealthy diet, smoking and excessive alcohol consumption) because these behaviors are often used by individuals as a mechanism to cope with stress (McEwen, 2012; Danese and McEwen, 2013).

In observational studies, the association between childhood SEP and subclinical atherosclerosis seems to be mediated by adulthood SEP, health-related behaviors and proximal risk factors for cardiovascular disease such as diabetes, hypertension and obesity; however, in some studies, the gradient remained after adjustment for those variables (Lamont et al., 2000; Lemelin et al., 2009; Carson et al., 2007), suggesting that additional pathways (e.g., stress) might play a role. In 1997, using data from the Whitehall II study, Marmot and colleagues reported that job control explained the excess risk of coronary heart disease for approximately $64 \%$ of men and $51 \%$ of women across occupational grades in the British civil service cohort (Marmot et al., 1997). According to these findings, job stress would also act as a mediator in the association between life course SEP and atherosclerosis because socioeconomic adversities in childhood, youth and early adulthood are related to an increased probability of having a low occupational grade and more stressful jobs in adulthood. However, little is known about the potential role of job stress in explaining the life course social gradient in subclinical markers of atherosclerosis, especially in upper-middle income countries such as Brazil.

Brazilian society has faced great economic and demographic changes in recent decades. Since 2001, the Gini index has been falling continuously (Instituto Brasileiro de Geografia e Estatística, 2012). In addition, the incomes of the poor have risen substantially, resulting in a decline in levels of poverty and misery. Thus, an important fraction of the population has experienced recent upward socioeconomic mobility, reflecting balanced economic growth, increases in the minimum wage, improvements in the labor market (such as declining unemployment and informal work) and anti-poverty policies such as cash transfer programs (Antigo and Machado, 2013; Kiggundu, 2012).

Despite these improvements, Brazil still has one of the highest inequalities in income distribution in the world, and this setting affects the burden of CVD. Findings from the National Household Survey in 2008 showed that the prevalence of self-reported diagnoses of heart disease and hypertension were approximately three times higher in individuals with 3 years of education or less compared to those with 11 years of education or more (Barros et al., 2011). In Porto Alegre, a large Brazilian city, $45 \%$ of premature CVD deaths were attributed to socioeconomic inequality (Bassanesi et al., 2008), and an ecological study performed with data for 98 Brazilian municipalities showed that death rates from premature CVD decreased by approximately 3.25 per 100,000 inhabitants for each $1 \%$ increase in the proportion of adults with high education levels (Ishitani et al., 2006). In addition, in São Paulo, the most populous city in Brazil, the trend of decline in deaths due to heart diseases from 1996 to 2010 was less pronounced among individuals living in the poorest area compared to those living in other areas (Lotufo et al., 2013).

Accordingly, using baseline data from the Brazilian Longitudinal Study of Adult Health (ELSA-Brasil), we examined whether life course SEP was related to carotid intima-media thickness (IMT), a surrogate marker of atherosclerosis. In addition, we tested the hypothesis that job stress can partially account for the life course socioeconomic gradient of IMT.

\section{Materials and methods}

\subsection{Data source and study population}

This study used baseline data from ELSA-Brasil (2008-2010), a multicenter cohort study of 15,105 civil servants (comprising 12,096 current workers and 3009 retired workers) of both genders, between 35 and 74 years of age, and enrolled in 5 universities and 1 research institute in six Brazilian states (São Paulo, Minas Gerais, Rio Grande do Sul, Bahia, Espírito Santo, and Rio de Janeiro). The ELSA-Brasil cohort comprises voluntary participants, and efforts were made to recruit similar proportions of men and women, as well as predefined proportions of age groups and occupational categories. More details about the study design, selection criteria and recruitment methods can be found elsewhere (Aquino et al., 2012). The baseline examination included a face-to-face interview and clinical, laboratory and anthropometric examinations. ELSABrasil protocol was approved at each of the six study centers by the local Institutional Review Board addressing research in human participants. Written informed consent was provided by all participants. 
For the current analyses, from the 15,105 participants in ELSABrasil baseline, we excluded retired workers $(n=3009)$ because the job stress scale only applied to current workers. We also excluded current workers with missing data in the job control or job demand subscales of the job stress scale $(n=32)$ and participants who either did not undergo IMT measurements or whose IMT image did not achieve the adequate quality $(n=3258)$. Thus, our final analytic sample comprised 8806 participants (73\% of the current workers in ELSA-Brasil).

\subsection{Study variables}

\subsubsection{Carotid IMT}

The ultrasound protocol to measure carotid IMT in the ELSABrasil study was described previously (Santos et al., 2014). Images of the common carotid artery were acquired within a region free of plaque in the outer wall of a pre-defined carotid segment of $1 \mathrm{~cm}$ in length from $1 \mathrm{~cm}$ below the carotid bifurcation during three cardiac cycles using a device (Aplio XG(tm), Toshiba) with a 7.5 MHz linear transducer. The images were collected and recorded at study sites and then sent to the centralized reading center in São Paulo for analysis using MIA ${ }^{\mathrm{TM}}$, an automated computer program. The IMT measurements were summarized as the minimum, maximum, and mean values of each common carotid artery (right and left). In this analysis, the IMT was defined as the mean of the right and left mean values (mean-mean).

\subsubsection{Job stress}

Job stress was evaluated using the Brazilian version of the Swedish Demand-Control-Support Questionnaire (DCSQ), which is based on the Job Content Questionnaire (Karasek, 1979). The DCSQ has three subscales (demand, control and support), but in this paper, we used only the demand and control dimensions. The psychological demands subscale comprises five items, four of which measure the pace and intensity of work, and one of which evaluates the occurrence of conflicting demands. The control subscale comprises six items, of which four evaluate skill discretion and two measure decision authority. All items were answered and scored on a 4-point Likert-scale ranging from 1 (often) to 4 (never/ almost never). The responses to each item were summed, with higher scores in the psychological demands (range from 5 to 20 points) and control subscales (range from 6 to 24 points) indicating higher levels of demand and control, respectively.

To define job strain following the Karasek's Demand-Control model (Karasek, 1979), the scores of the demand and control subscales were dichotomized in low ( $\leq$ median) versus high ( $>$ median). Then, we created a variable to classify the participants into four mutually exclusive groups to express the relationship between job demand and job control: low strain work (low demand/high control), passive work (low demand/low control), active work (high demand/high control), and high strain work (high demand/low control). We also evaluated the continuous scores for the demand and control dimensions separately.

\subsubsection{Life course SEP indicators}

Adulthood SEP was evaluated based on the social class of the current occupation, a summary measure based on three aspects: the current occupation held by the participant, the expected income based on the education level (average market value), and the observed income. First, the socioeconomic status was estimated using the mean between the expected and observed income for each participant. Second, for each occupational title, the mean score of the socioeconomic status of individuals was estimated to obtain the occupational socioeconomic status. Then, using these occupational socioeconomic status scores, strata grouping was defined to achieve a minimum intra-stratum variance of the values of the scores and a maximum variation between the strata. Thus, these scores were categorized into 7 levels (high-upper, high-low, middle-upper, middle-middle, middle-low, low-high and low-low).

Youth SEP was measured based on the social class of the first occupation, which was obtained using the same approach used to obtain the social class of the current occupation but based on the first job held by the participant. For the current analysis, both measures of social class were summarized in three categories: high (high-upper and high-low), middle (middle-upper, middle-middle and middle-low), and low (low-high and low-low).

Childhood SEP was evaluated based on maternal education, and it was assessed retrospectively by self-report of years of schooling using the question What is your mother's educational level? The responses to this question were categorized into four groups: $\geq 11$, $8-10,1-7$, and 0 years of study.

To indicate the accumulation of risk during the life course, a cumulative SEP score was generated; these scores ranged between zero and six (higher values reflect a lower life course SEP) and included maternal education ( $\geq 11$ years of study $=0 ; 1-10$ years of study $=1 ; 0$ years of study $=2$ ), social class of first occupation (high $=0$; middle $=1$; low $=2$ ) and social class of current occupation (high $=0$; middle $=1$; low $=2$ ). Among men, this score ranged from zero to four because maternal education was not associated with IMT in the minimally adjusted model in men.

\subsubsection{Other sociodemographic variables}

Three demographic characteristics were assessed as covariates: gender, age, and race, with categories used in the Brazilian Census (White, Brown, Black, other).

\subsection{Data analysis}

All analyses were conducted separately for men and women because results from previous studies have suggested differences in the associations of interest by gender. We generated descriptive characteristics of the analytic sample. In addition, we performed a comparison between the current workers included in this analysis and those excluded using chi-square tests to compare categorical variables, Wilcoxon rank-sum tests to compare medians and t-tests to compare means. We estimated the prevalence of each category of job strain by Karasek's model and low control ( $\leq$ median) and high demand (>median) according to the level of life course SEP. Chi-square tests were performed on group differences. All descriptive analyses were performed using complete case analysis.

We constructed a directed acyclic graph (DAG) of proposed associations between life course socioeconomic position and subclinical atherosclerosis (IMT) in adulthood to guide our analyses (Fig. 1). Following this DAG, to investigate the mediating role of job strain on the association between life course SEP and IMT, we could not condition on health-related behaviors or markers of metabolic, endocrine and immune dysregulation because all of these variables are colliders (i.e., their inclusion in the regression would induce bias) (VanderWeele and Robins, 2007).

Linear regression models were performed with IMT as the outcome of interest. First, we assessed the association of age and race with IMT. Second, we evaluated the association of job stress and each life course SEP indicator with IMT adjusted by age and race. We also examined the association between SEP indicators and IMT, including all SEP indicators simultaneously in the model. Then, we separately added into this model the job characteristics that were statistically associated with IMT and were also associated with SEP (according to the chi-square tests) to evaluate the mediating role of job stress. In addition, we evaluated the association 


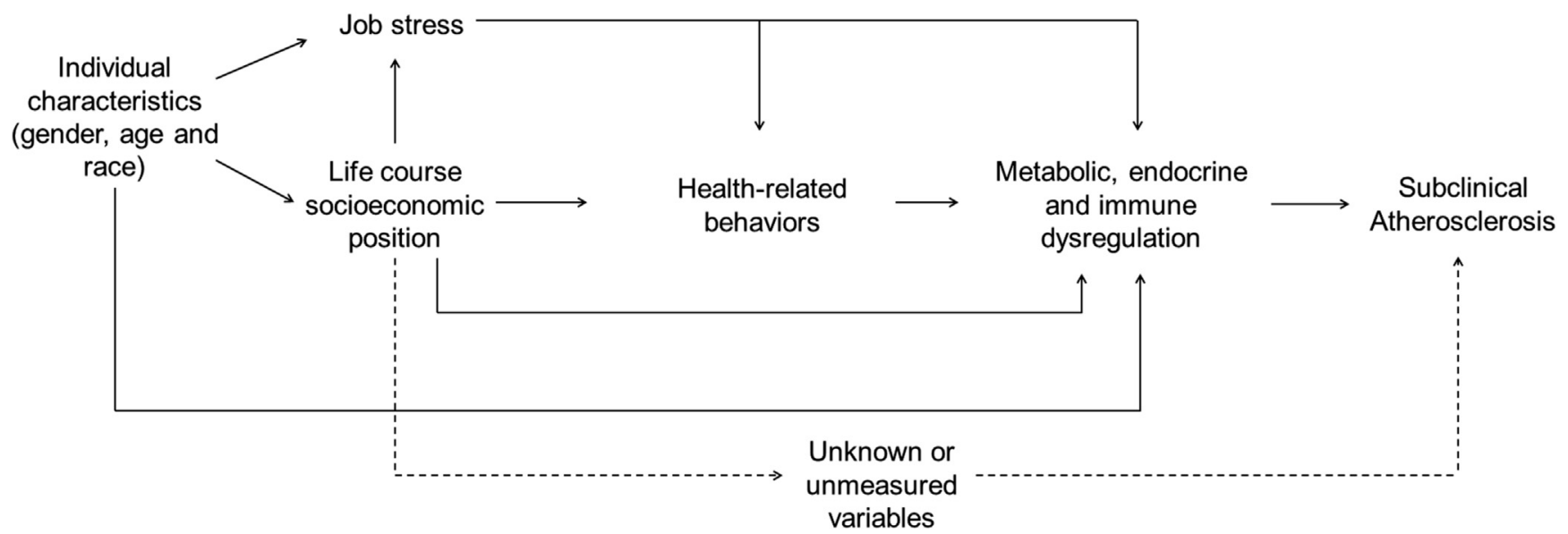

Fig. 1. A directed acyclic graph (DAG) showing the association between life course socioeconomic position and subclinical atherosclerosis in adulthood.

between cumulative SEP score and IMT adjusted by age and race, and then we also separately added the job characteristics that were statistically associated with IMT and SEP indicators to evaluate the mediating role of job stress in this association. Regression coefficients $\beta$ and their 95\% confidence intervals (CI) were reported, and they represent the difference in IMT in millimeters $(\mathrm{mm})$.

The significance level was set at 0.05 , and all analyses were conducted using the software Stata 13.0 (Stata Corporation, College Station, TX, United States).

\subsubsection{Missing data}

We performed multivariate imputation by chained equations with missing-at-random assumptions (White et al., 2011) to impute the explanatory variables for missing data (race: $\mathrm{n}=87$; maternal education: $n=170$ : social class of first occupation: $n=1302$; social class of current occupation: $n=126$ ). Twenty copies of the data, with the missing values properly imputed, were independently assessed in multivariate linear regression models. Estimates of $\beta$ coefficients were averaged across the 20 copies to give a single mean estimate, and standard errors were adjusted according to Rubin's rules (White et al., 2011). The variables in the imputed model were age, race, sex, maternal education, social class of first occupation, social class of current occupation, job stress by Karasek's model, IMT, and participant's own education. Sensitivity analyses conducted in the complete cases analysis without imputation yielded largely similar results.

\section{Results}

Descriptive characteristics of the analytical sample and comparison with current workers in ELSA-Brasil excluded from the analysis are presented in Table 1. The mean IMT was $0.887 \mathrm{~mm}$, and on average, men presented a higher IMT than women $(0.921 \mathrm{~mm}$ versus $0.858 \mathrm{~mm}, \mathrm{p}<0.001$ ). Overall, participants with a lower SEP in different stages of life had a higher prevalence of passive work, high-strain jobs, and low job control. On the other hand, higher prevalences of low-strain jobs, active work and high demand were found in individuals with a higher life course SEP (Table 2).

In both genders, IMT was strongly and linearly associated with age and increased by $0.011 \mathrm{~mm}$ for each additional year of life (Table 3). Men and women who reported that they were Black, as well as women who reported they were Brown, presented higher IMT compared with White participants. Job demands were not associated with IMT in either gender, and higher scores on the job control subscale were associated with lower IMT values only in
Table 1

Descriptive characteristics of the sample and comparison with current workers of ELSA-Brasil excluded from this analysis. Brazilian Longitudinal Study of Adult Health (ELSA-Brasil), 2008-2010.

\begin{tabular}{|c|c|c|}
\hline Characteristics $^{\mathrm{a}}$ & $\begin{array}{l}\text { Included } \\
N=8806^{\mathrm{b}}\end{array}$ & $\begin{array}{l}\text { Excluded } \\
N=3290^{\mathrm{b}}\end{array}$ \\
\hline \multicolumn{3}{|l|}{ Age (years), \% } \\
\hline $35-44$ & $2471(28.1)$ & $866(26.3)$ \\
\hline $45-54$ & $4173(47.4)$ & $1588(48.3)$ \\
\hline $55-64$ & $1982(22.5)$ & $755(23.0)$ \\
\hline \multirow[t]{2}{*}{$65-72$} & $180(2.0)$ & $81(2.5)$ \\
\hline & $P$-value ${ }^{c}=0.161$ & \\
\hline \multicolumn{3}{|l|}{ Sex, \% } \\
\hline Men & $4077(46.3)$ & $1703(51.8)$ \\
\hline Women & $\begin{array}{l}4729(53.7) \\
P \text {-value }<0.001\end{array}$ & $1587(48.2)$ \\
\hline \multicolumn{3}{|l|}{ Race, \% } \\
\hline White & $4762(54.6)$ & $1323(40.9)$ \\
\hline Brown & $2302(26.4)$ & $1198(37.0)$ \\
\hline Black & $1336(15.3)$ & $619(19.1)$ \\
\hline \multirow[t]{2}{*}{ Other } & $319(3.7)$ & $96(3.0)$ \\
\hline & $P$-value ${ }^{\mathrm{C}}<0.001$ & \\
\hline \multicolumn{3}{|l|}{ Maternal education(years of study), \% } \\
\hline$\geq 11$ & $2042(23.7)$ & $900(28.1)$ \\
\hline$\overline{8}-10$ & $1697(19.7)$ & $619(19.3)$ \\
\hline $1-7$ & $3733(43.2)$ & $1322(41.3)$ \\
\hline \multirow[t]{2}{*}{0} & 1164 (13.5) & $362(11.3)$ \\
\hline & $P$-value ${ }^{\mathrm{C}}<0.001$ & \\
\hline \multicolumn{3}{|l|}{ Social Class of first occupation, \% } \\
\hline High & $503(6.7)$ & $226(8.2)$ \\
\hline Middle & $2440(32.5)$ & $871(31.6)$ \\
\hline \multirow{2}{*}{ Low } & $4561(60.8)$ & $1658(60.2)$ \\
\hline & $P$-value ${ }^{c}=0.030$ & \\
\hline \multirow[t]{2}{*}{ Age at first job, (years), mean (SD) } & 17.2 & 17.7 \\
\hline & $P$-value ${ }^{\mathrm{C}}<0.001$ & \\
\hline \multicolumn{3}{|l|}{ Social class of current occupation, \% } \\
\hline High & $2647(30.5)$ & $1099(33.8)$ \\
\hline Middle & $3871(44.6)$ & $1534(47.2)$ \\
\hline \multirow[t]{2}{*}{ Low } & $2162(24.9)$ & $619(19.0)$ \\
\hline & $P$-value ${ }^{c}<0.001$ & \\
\hline \multirow[t]{2}{*}{ Job control, median (IQR) } & $18(16-20)$ & $18(16-20)$ \\
\hline & $P$-value ${ }^{\mathrm{C}}=0.596$ & \\
\hline \multirow[t]{2}{*}{ Job demand, median (IQR) } & $14(11-15)$ & $14(11-15)$ \\
\hline & $P$-value ${ }^{\mathrm{C}}=0.481$ & \\
\hline \multicolumn{3}{|l|}{ Job strain by Karasek's model, \% } \\
\hline Low strain & $2111(24.0)$ & $753(23.1)$ \\
\hline Passive & $2934(33.3)$ & $1072(32.9)$ \\
\hline Active & $1896(21.5)$ & $742(22.8)$ \\
\hline \multirow[t]{2}{*}{ High strain } & $1865(21.2)$ & $691(21.2)$ \\
\hline & $P$-value ${ }^{c}=0.467$ & \\
\hline
\end{tabular}

${ }^{\text {a }} N(\%)$ or mean (Standard Deviation $-S D$ ) or median (Interquartile Range - IQR)

b Differences in total $N$ for each variable are due to missing values.

c Chi-square test was used to compare groups in categorical variable, Wilcoxon rank-sum test was used to compare medians and T-test was used to compare means. 
Table 2

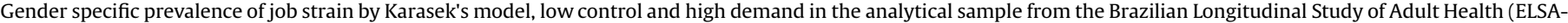
Brasil), 2008-2010.

\begin{tabular}{|c|c|c|c|c|c|c|c|c|c|c|c|c|}
\hline \multirow[t]{3}{*}{ Characteristics } & \multicolumn{6}{|c|}{ Men $N=4077$} & \multicolumn{6}{|c|}{ Women $N=4729$} \\
\hline & \multicolumn{4}{|c|}{ Job strain by Karasek's model } & \multirow{2}{*}{$\begin{array}{l}\text { Low } \\
\text { control } \\
(\%)\end{array}$} & \multirow{2}{*}{$\begin{array}{l}\text { High } \\
\text { demand } \\
(\%)\end{array}$} & \multicolumn{4}{|c|}{ Job strain by Karasek's model } & \multirow{2}{*}{$\begin{array}{l}\text { Low } \\
\text { control } \\
(\%)\end{array}$} & \multirow{2}{*}{$\begin{array}{l}\text { High } \\
\text { demand } \\
(\%)\end{array}$} \\
\hline & $\begin{array}{l}\text { Low } \\
\text { strain } \\
(\%)\end{array}$ & $\begin{array}{l}\text { Passive } \\
(\%)\end{array}$ & $\begin{array}{l}\text { Active } \\
(\%)\end{array}$ & $\begin{array}{l}\text { High strain } \\
(\%)\end{array}$ & & & $\begin{array}{l}\text { Low } \\
\text { strain } \\
(\%)\end{array}$ & $\begin{array}{l}\text { Passive } \\
(\%)\end{array}$ & $\begin{array}{l}\text { Active } \\
(\%)\end{array}$ & $\begin{array}{l}\text { High } \\
\text { strain } \\
(\%)\end{array}$ & & \\
\hline \multicolumn{13}{|c|}{ Maternal education (years of study) } \\
\hline$\geq 11$ & 34.4 & 15.4 & 37.1 & 13.1 & 28.5 & 50.2 & 34.8 & 21.8 & 29.4 & 14.1 & 35.8 & 43.4 \\
\hline $8-10$ & 24.4 & 26.9 & 28.7 & 20.0 & 46.9 & 48.7 & 25.6 & 32.1 & 20.6 & 21.8 & 53.9 & 42.4 \\
\hline $1-7$ & 21.0 & 35.3 & 18.7 & 24.9 & 60.2 & 43.6 & 20.7 & 39.4 & 16.8 & 23.2 & 62.6 & 39.9 \\
\hline 0 & 15.7 & 45.7 & 13.1 & 25.5 & 71.2 & 38.6 & 13.5 & 51.6 & 9.8 & 25.0 & 76.7 & 34.9 \\
\hline P-value ${ }^{\mathrm{a}}$ & $P<0.0$ & & & & $P<0.001$ & $P<0.001$ & $P<0.001$ & & & & $P<0.001$ & $P=0.004$ \\
\hline \multicolumn{13}{|c|}{ Social class of first occupation } \\
\hline High & 39.2 & 8.6 & 40.2 & 12.0 & 20.6 & 52.2 & 42.5 & 13.3 & 32.0 & 12.2 & 25.5 & 44.2 \\
\hline Middle & 28.8 & 22.9 & 31.0 & 17.3 & 40.3 & 48.3 & 26.6 & 31.6 & 21.7 & 20.2 & 51.7 & 41.9 \\
\hline Low & 18.5 & 38.5 & 17.2 & 25.8 & 64.3 & 43.0 & 17.4 & 43.1 & 14.3 & 25.3 & 68.4 & 39.6 \\
\hline P-value $e^{a}$ & $P<0.0$ & & & & $P<0.001$ & $P=0.002$ & $P<0.001$ & & & & $P<0.001$ & $P=0.175$ \\
\hline \multicolumn{13}{|l|}{ Social class } \\
\hline High & 38.1 & 9.3 & 44.2 & 8.4 & 17.7 & 52.6 & 38.0 & 12.5 & 37.4 & 12.2 & 24.7 & 49.6 \\
\hline Middle & 19.8 & 36.5 & 17.0 & 26.8 & 63.3 & 43.8 & 20.6 & 42.0 & 14.4 & 23.1 & 65.1 & 37.4 \\
\hline Low & 14.9 & 46.5 & 10.9 & 27.8 & 74.3 & 38.6 & 10.2 & 54.7 & 6.0 & 29.1 & 83.8 & 35.0 \\
\hline P-value ${ }^{\mathrm{a}}$ & $P<0.0$ & & & & $P<0.001$ & $P<0.001$ & $P<0.001$ & & & & $P<0.001$ & $P<0.001$ \\
\hline
\end{tabular}

a The p-values are from the chi-square tests.

women. High strain and passive work were associated with higher IMT in women, whereas among men only high strain was associated with higher IMT (Table 3).

Low maternal education (childhood SEP) was not associated with higher IMT in men, but it was in women. Low social class of first occupation (youth SEP) was associated with higher IMT in both

Table 3

Associations of age, race/color, life course socioeconomic position and job stress indicators with intima-media thickness. Brazilian Longitudinal Study of Adult Health (ELSA-Brasil), 2008-2010.

\begin{tabular}{|c|c|c|}
\hline \multirow[t]{2}{*}{ Indicators } & \multirow{2}{*}{$\frac{\text { Men }(N=4077)}{\beta(95 \% C I)}$} & \multirow{2}{*}{$\frac{\text { Women }(N=4729)}{\beta(95 \% C I)}$} \\
\hline & & \\
\hline Age & $0.011(0.010 ; 0.012)^{* * *}$ & $0.011(0.010 ; 0.012)^{* * *}$ \\
\hline \multicolumn{3}{|l|}{ Race } \\
\hline White & Ref & Ref \\
\hline Brown & $-0.003(-0.017 ; 0.012)$ & $0.021(0.010 ; 0.033)^{* * *}$ \\
\hline Black & $0.048(0.029 ; 0.067)^{* * *}$ & $0.057(0.044 ; 0.070)^{* * *}$ \\
\hline Other & $0.030(-0.005 ; 0.066)$ & $0.020(-0.005 ; 0.045)$ \\
\hline \multicolumn{3}{|c|}{ Job stress indicators (adjusted by age and race/color) } \\
\hline Job control & $-0.002(-0.004 ; 0.000)$ & $-0.002(-0.004 ;-0.001)^{* *}$ \\
\hline Job demand & $-0.002(-0.000 ; 0.004)$ & $-0.000(-0.002 ; 0.001)$ \\
\hline \multicolumn{3}{|c|}{ Job strain by Karasek's model } \\
\hline Low strain & Ref & Ref \\
\hline Passive & $0.012(-0.004 ; 0.028)$ & $0.022(0.011 ; 0.033)^{* * *}$ \\
\hline Active & $0.006(-0.010 ; 0.023)$ & $0.007(-0.006 ; 0.020)$ \\
\hline High strain & $0.028(0.010 ; 0.045)^{* *}$ & $0.014(0.001 ; 0.026)^{*}$ \\
\hline \multicolumn{3}{|c|}{$\begin{array}{l}\text { Life course socioeconomic position indicators (adjusted by age and race/ } \\
\text { color) }\end{array}$} \\
\hline \multicolumn{3}{|c|}{ Maternal education(years of study) } \\
\hline$\geq 11$ & Ref & Ref \\
\hline$\overline{8}-10$ & $-0.000(-0.018 ; 0.017)$ & $0.004(-0.009 ; 0.017)$ \\
\hline $1-7$ & $0.004(-0.011 ; 0.019)$ & $0.003(-0.008 ; 0.014)$ \\
\hline 0 & $-0.005(-0.025 ; 0.015)$ & $0.024(0.009 ; 0.040)^{* *}$ \\
\hline \multicolumn{3}{|c|}{ Social class of first occupation } \\
\hline High & Ref & Ref \\
\hline Middle & $0.014(-0.012 ; 0.040)$ & $0.001(-0.017 ; 0.018)$ \\
\hline Low & $0.033(0.008 ; 0.059)^{*}$ & $0.019(0.002 ; 0.036)^{*}$ \\
\hline \multicolumn{3}{|c|}{ Social class of current occupation } \\
\hline High & Ref & Ref \\
\hline Middle & $0.025(0.011 ; 0.040)^{* *}$ & $0.018(0.008 ; 0.028)^{* * *}$ \\
\hline Low & $0.035(0.020 ; 0.050)^{* * *}$ & $0.035(0.022 ; 0.047)^{* * *}$ \\
\hline
\end{tabular}

Notes: Regression coefficients $\beta$ represent the difference in intima-media thickness in millimeter $(\mathrm{mm}),{ }^{*} P<0.05,{ }^{* *} P<0.01,{ }^{* * *} P<0.001, C I=$ confidence interval. genders, and the lower the social class of the current occupation (adulthood SEP), the higher the IMT was in both genders (Table 3). The simultaneous adjustment for all SEP indicators showed that only adulthood SEP continued to be statistically associated with greater IMT in men and women (Table 4).

In both genders, the association between each SEP indicator and the IMT changed minimally after adjustment for job strain, and only the passive work among women remained borderline associated with IMT after adjustment for SEP indicators. The same situation was observed using the job control as the adjustment variable among women (Table 4).

Higher IMT values were observed in men sequentially exposed to low SEP in youth and adulthood and among women sequentially exposed to low SEP in childhood, youth and adulthood. The association between cumulative SEP score and IMT changed minimally after adjustment for job strain (in both genders) and job control (among women) (Table 5).

\section{Discussion}

Exposure to social disadvantage in youth and adulthood were associated with higher IMT in both genders; however, low childhood SEP was associated with higher IMT only among women. Childhood and youth SEP were not associated with IMT independent of adulthood SEP. However, in both genders, the higher IMT values were observed among individuals sequentially exposed to low SEP in more than one period of life. Thus, exposure to social adversity in childhood and youth seems to play a role in IMT when it is considered together with adulthood SEP, providing support for a model of cumulative effects of exposures to SEP across the life course. We also found that job stress failed to explain the higher IMT among participants with social disadvantage over the life span.

The biggest differences in IMT were found when the cumulative SEP score was used as an indicator of SEP. Using this indicator, the difference between high and low SEP was on the order of $0.051 \mathrm{~mm}$ for men and $0.037 \mathrm{~mm}$ for women. Although the magnitude of this difference may seem modest, it is equivalent to the change in IMT that would occur in approximately five additional years of age in men and in approximately three additional years of age in women in this same cohort. In addition, a prior meta-analysis highlighted 
Table 4

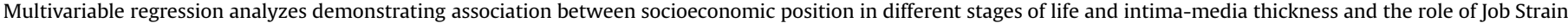
(Karasek's Model) and job control (in women) ${ }^{\mathrm{a}}$ in this gradient according to gender. Brazilian longitudinal study of adult health (ELSA-Brasil), 2008-2010, $(N=8806)$.

\begin{tabular}{|c|c|c|c|c|c|}
\hline \multirow[t]{3}{*}{ Indicators } & \multicolumn{5}{|l|}{ Model adjustment } \\
\hline & \multicolumn{2}{|c|}{$\begin{array}{l}\text { Age, race, all socioeconomic position indicators } \\
\text { simultaneously }\end{array}$} & \multicolumn{2}{|c|}{$\begin{array}{l}\text { Age, race, all socioeconomic position indicators } \\
\text { simultaneously and job strain (Karasek's model) }\end{array}$} & \multirow{2}{*}{$\begin{array}{l}\text { Age, race, all socioeconomic position } \\
\text { indicators simultaneously and job control } \\
\text { Women } \beta(95 \% C I)^{c}\end{array}$} \\
\hline & $\operatorname{Men}^{\mathrm{b}} \beta(95 \% C I)^{\mathrm{c}}$ & Women $\beta(95 \% C I)^{c}$ & $\operatorname{Men}^{\mathrm{b}} \beta(95 \% C I)^{\mathrm{c}}$ & Women $\beta(95 \% C I)^{c}$ & \\
\hline \multicolumn{6}{|c|}{ Maternal education (years of study) } \\
\hline$\geq 11$ & & Ref & & Ref & Ref \\
\hline $8-10$ & & $-0.002(-0.015 ; 0.011)$ & & $-0.002(-0.016 ; 0.011)$ & $-0.002(-0.015 ; 0.011)$ \\
\hline $1-7$ & & $-0.006(-0.018 ; 0.005)$ & & $-0.007(-0.019 ; 0.005)$ & $-0.006(-0.018 ; 0.005)$ \\
\hline 0 & & $0.008(-0.009 ; 0.025)$ & & $0.007(-0.010 ; 0.024)$ & $0.008(-0.009 ; 0.024)$ \\
\hline \multicolumn{6}{|c|}{ Social class of first occupation } \\
\hline High & Ref & Ref & Ref & Ref & Ref \\
\hline Middle & $0.007(-0.019 ; 0.034)$ & $-0.006(-0.024 ; 0.012)$ & $0.007(-0.019 ; 0.034)$ & $-0.007(-0.025 ; 0.011)$ & $-0.006(-0.024 ; 0.012)$ \\
\hline Low & $0.018(-0.009 ; 0.045)$ & $0.007(-0.012 ; 0.025)$ & $0.018(-0.009 ; 0.045)$ & $0.006(-0.013 ; 0.024)$ & $0.006(-0.012 ; 0.025)$ \\
\hline \multicolumn{6}{|c|}{ Social class of current occupation } \\
\hline High & Ref & Ref & Ref & Ref & Ref \\
\hline Middle & $0.021(0.005 ; 0.036)^{* *}$ & $0.016(0.005 ; 0.027)^{* *}$ & $0.021(0.004 ; 0.037)^{*}$ & $0.014(0.003 ; 0.026)^{*}$ & $0.016(0.004 ; 0.027)^{* *}$ \\
\hline Low & $0.028(0.012 ; 0.045)^{* *}$ & $0.029(0.015 ; 0.043)^{* * *}$ & $0.028(0.010 ; 0.047)^{* *}$ & $0.026(0.011 ; 0.041)^{* * *}$ & $0.028(0.013 ; 0.043)^{* * *}$ \\
\hline \multicolumn{6}{|c|}{ Job strain by Karasek's model } \\
\hline Low strain & & & Ref & Ref & \\
\hline Passive & & & $-0.000(-0.017 ; 0.016)$ & $0.013(0.002 ; 0.025)^{*}$ & \\
\hline Active & & & $0.009(-0.008 ; 0.025)$ & $0.009(-0.004 ; 0.022)$ & \\
\hline High strain & & & $0.017(-0.001 ; 0.035)$ & $0.007(-0.006 ; 0.020)$ & \\
\hline Job control & & & & & $-0.000(-0.002 ; 0.001)$ \\
\hline
\end{tabular}

a The analysis using the adjustment by job control was performed only in women, because job control was not associated with intima-media thickness in the minimally adjusted model.

b Maternal education was not included in the adjusting model in men, since it was not associated with intima-media thickness in the minimally adjusted model.

c Regression coefficients $\beta$ represent the difference in intima-media thickness in millimeter $(\mathrm{mm}),{ }^{*} P<0.05,{ }^{* *} P<0.01$, ${ }^{* * *} P<0.001, \mathrm{CI}=$ confidence interval.

that for each increase of $0.1 \mathrm{~mm}$ of IMT, the risk of myocardial infarction increases by $15 \%$, while the risk of stroke increases by $18 \%$ (Lorenz et al., 2007).

We found that childhood SEP was associated with IMT only among women, which is similar with founds from the general Swedish population (Rosvall et al., 2002), and in the Newcastle Thousand Families birth cohort (Lamont et al., 2000). In the Multi-
Ethnic Study of Atherosclerosis (MESA), the researchers found that childhood SEP and adulthood SEP were independently associated with IMT in adulthood in both genders. However, the association was stronger among women (Lemelin et al., 2009). The explanation for the gender difference in the association between early life course SEP and IMT remains unclear. Childhood SEP has been found to be more strongly associated with age at natural menopause than

Table 5

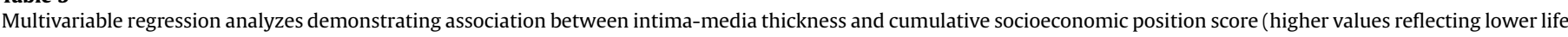

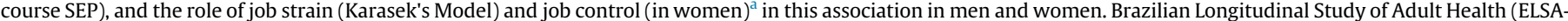
Brasil), 2008-2010.

\begin{tabular}{|c|c|c|c|}
\hline \multirow[t]{3}{*}{ Cumulative SEP } & \multicolumn{3}{|c|}{ Model adjustment } \\
\hline & Age and race & $\begin{array}{l}\text { Age, race, and job strain } \\
\text { (Karasek's model) }\end{array}$ & Age, race, and job control ${ }^{\mathrm{a}}$ \\
\hline & $\beta(95 \% C I)^{\mathrm{b}}$ & & \\
\hline
\end{tabular}

\section{Men $(\mathrm{N}=\mathbf{4 0 7 7})$}

Cumulative socioeconomic position score (youth and adulthood)

0 (high socioeconomic position in both periods) Ref 1

2

$0.013(-0.017 ; 0.043)$

$0.026(-0.003 ; 0.055)$

$0.037(0.009 ; 0.066)^{*}$

$0.051(0.022 ; 0.079)^{* *}$

4 (low socioeconomic position in both periods)

Women ( $\mathbf{N}=\mathbf{4 7 2 9})$

Cumulative socioeconomic position score (childhood, youth and adulthood)

0 (high socioeconomic position in the three periods) Ref

1

2

4

5

6 (low socioeconomic position in the three periods)
Ref

$0.013(-0.017 ; 0.042)$

$0.025(-0.004 ; 0.054)$

$0.036(0.007 ; 0.065)^{*}$

$0.049(0.020 ; 0.079)^{*}$

$\begin{array}{ll}\text { Ref } & \text { Ref } \\ -0.013(-0.040 ; 0.015) & -0.013(-0.040 ; 0.015) \\ -0.010(-0.036 ; 0.016) & -0.012(-0.038 ; 0.015) \\ 0.001(-0.025 ; 0.025) & -0.003(-0.028 ; 0.023) \\ 0.012(-0.013 ; 0.037) & 0.008(-0.017 ; 0.034) \\ 0.023(-0.003 ; 0.049) & 0.018(-0.008 ; 0.045) \\ 0.037(0.006 ; 0.068)^{*} & 0.031(0.001 ; 0.063)^{*}\end{array}$

Ref

$-0.013(-0.040 ; 0.015)$

$-0.010(-0.036 ; 0.016)$

$-0.001(-0.026 ; 0.025)$

$0.011(-0.014 ; 0.036)$

$0.021(-0.006 ; 0.048)$

$0.035(0.003 ; 0.066)^{*}$

\footnotetext{
a The analysis using the adjustment by job control was done only among women, because job control was not associated with intima-media thickness in the minimally adjusted model.

${ }^{\mathrm{b}}$ Regression coefficients $\beta$ represent the difference in intima-media thickness in millimeter $(\mathrm{mm}),{ }^{*} P<0.05,{ }^{* *} P<0.01,{ }^{* * *} P<0.001, C I=$ confidence interval

c Cumulative SEP score among men did not include childhood socioeconomic position (maternal education), since this indicator was not associated with intima-media
} thickness in minimally adjusted model. 
is adulthood SEP (Mishra et al., 2009), and early menopause appears to be associated with increased IMT and other markers of atherosclerosis (El Khoudary et al., 2013). Moreover, it is known that men have higher mortality than women at every age (Barford et al., 2006), and early-life socioeconomic disadvantages are associated with higher mortality (Stringhini et al., 2011). Thus, it is possible that men exposed to low maternal education had higher risk of dying before they had the opportunity to participate in the study than women with the same exposure. If this hypothesis is correct, we could be underestimating the magnitude of the association between maternal education and IMT values in men.

The association of childhood SEP and youth SEP with IMT disappeared after considering adulthood SEP in the multivariate model. Because exposure to low SEP in early life could increase the chances of subsequent exposure in adulthood, these results suggest that the association of childhood and youth SEP with IMT is mediated by current SEP. According to the "chain of risk" hypothesis, these links are probabilistic rather than deterministic but are likely to be sequential, and when each adverse experience increases the probability of disease in a cumulative fashion, this might characterize an "additive effect" or a special case of accumulation risk model (Kuh et al., 2003; Lynch and Smith, 2005; Ben-Shlomo and Kuh, 2002; Kuh et al., 2004). In our study, this additive effect was observed when we examined the association between cumulative SEP score and IMT because the highest IMT values were observed in individuals sequentially exposed to low SEP in more than one period of life. The atherosclerotic process is evident very early in life (Stary, 2000), develops gradually as a subclinical condition across the life course, and can lead to cardiovascular clinical events. The natural history of this disease is compatible with the cumulative effect of exposure to social adversities across the life course that we found in this study. Moreover, our findings are also consistent with the notion of allostatic load because the number and duration of stress exposures could increase the damage to biological systems (McEwen, 2012; Danese \& McEwen, 2013). The cumulative effect of exposure to social adversities across the life course on IMT was also observed in participants of the Atherosclerosis Risk in Communities Study (ARIC) (Carson et al., 2007). Nevertheless, in the general population of Sweden, this cumulative effect of SEP on carotid stenosis was observed only among women (Rosvall et al., 2002), and the association between cumulative life course SEP and subclinical atherosclerosis, measured by the anklebrachial index, was observed only among men (Agha et al., 2011).

Job strain and job control failed to explain the increased IMT among participants with social disadvantage over the life span, and these job characteristics were not independently associated with IMT in either gender, with the exception of the association of passive work with IMT among women, which presented borderline significance. Because of this, it was not necessary to perform a specific method to evaluate the mediation role of job stress because most of these variables did not meet one of the basic principles of mediation, which is that the mediator must be independently associated with the outcome (Baron and Kenny, 1986). Our results depart from those reported in the Whitehall II study, which found that job control explained between $51 \%$ and $64 \%$ of the occupational gradient in coronary heart disease (CHD) among women and men, respectively (Marmot et al., 1997). We used the IMT as the outcome whereas Whitehall used incidence of self-reported coronary heart disease, which is more susceptible to information bias. Other studies that used direct evaluation of incidence or mortality by myocardial infarction rather than self-reported CVD as the outcome have also failed to demonstrate that job stress substantially explains the social gradient in CVD (Wamala et al., 2000; Kuper et al., 2006; Huisman et al., 2008). For cerebrovascular disease, the mediating role of job characteristics is even less clear, and we know that IMT predicts cerebrovascular events better than coronary events (Lorenz et al., 2007). For example, among women in the Finnish Public Sector Study, the social gradient in the incidence of cerebrovascular events increased after considering the role of job control and job demand (Kivimäki et al., 2009), while in the Women's Lifestyle and Health cohort, job strain was unrelated to stroke risk (Kuper et al., 2007). In addition to the Whitehall II study, there are also some studies that have identified some mediating role of job stress; however, the percent reduction in the socioeconomic gradient in CVD attributable to job control or job strain was less expressive (Virtanen and Notkola, 2002; Ferrario et al., 2011; Toivanen and Hemström, 2006).

Health-related behaviors (e.g., smoking, physical inactivity, unhealthy diet, excessive alcohol consumption) and metabolic dysregulation (e.g., obesity, diabetes, hypertension, chronic inflammation, dyslipidemia) are common effects of life course SEP and job stress. In other words, they are colliders. Thus, the inclusion of all these variables together in the regression models to investigate the effect of job stress in the social gradient would induce collider bias ${ }^{56}$. However, we know that these conventional risk factors for CVD are important in explaining the social gradient in subclinical atherosclerosis, as this has been reported in many studies (Lamont et al., 2000; Lemelin et al., 2009; Kivimäki et al., 2005). These findings could be the result of confounding or mediation processes. Nevertheless, we believed that this effect is predominantly of mediation, as we showed in our DAG (Fig. 1). Healthrelated behaviors are often used by individuals as a mechanism to cope with the stress caused by social adversities or job stress. In addition, metabolic dysregulation can result in prolonged activation of the allostatic systems from social adversities or job stress (McEwen, 2012; Danese \& McEwen, 2013). Thus, health-related behaviors and metabolic dysregulation are proximal causes of cardiovascular disease, and they are products of many distal causes, such as socioeconomic position and job stress across the life course. This theoretic framework supports our decision to not consider conventional risk factors in our analysis because our aim was not to investigate the mediation role of conventional risk factors for CVD to explain the SEP gradient on IMT but rather to investigate the mediation role of job stress.

\subsection{Limitations}

Some potential strengths and limitations of our analysis merit consideration. First, the outcome in this study is a subclinical condition and, consequently, it is unlikely that biological changes even without clinical signs and symptoms could have influenced the SEP in a downward direction, particularly early SEP. Thus, although this study is a cross-section analysis, reverse causality is probably not a limitation of this paper. Second, many studies have used participants' own education as a youth SEP indicator because education is generally complete in late adolescence or in the beginning of adult life (Galobardes et al., 2007). However, we used as the indicator of youth SEP the social class of the first occupation because this indicator is probably a better indicator of youth than is education in ELSA-Brasil, as the mean age that the participants started to work in this cohort was 17 years old, and the participants' own education could be finished in later stages of life. Third, we used only maternal education to measure childhood SEP, and other studies that have used additional indicators of SEP in childhood, such as in utero SEP and parental occupational status, could provide a better evaluation of social adversities in childhood because this construct is multidimensional. Fourth, small differences were observed when comparing included versus excluded participants, and our analytical sample tended to have lower life course SEP than did the excluded participants. However, these differences were 
small, and it is likely that the significance tests were inflated by our large sample size. The excluded group also had a lower proportion of White individuals and a higher proportion of men. Nevertheless, the proportions of each gender and race in the included group were very similar to the entire cohort of ELSA-Brasil, and our analysis was performed stratifying by gender and adjusting by race. Thus, we believe that these differences did not impact our findings. Fifth, the ELSA-Brasil participants are all employed in the civil service, whose employees have higher average education and income levels compared to the rest of the population of Brazil. Thus, people who experienced extreme social difficulties in childhood as well as in adulthood may not be represented in this study. The truncated variability in SEP may have led us to underestimate the magnitude of the associations between life course SEP and IMT values.

\section{Conclusion}

Our study demonstrated that the exposures to social adversities in youth and adulthood were associated with higher IMT in both genders but that childhood SEP seems to play a role only among women. Both measures of early SEP were not associated with IMT independent of adulthood SEP. However, in both genders, higher IMT values were observed among individuals sequentially exposed to low SEP in more than one period of life, providing support for a model of the cumulative effects of exposures to SEP across the life span. We did not find that job stress (defined as low job control or job strain) explained the association between low SEP and higher IMT, suggesting that strategies to address socioeconomic inequalities in CVD should target additional steps beyond reducing job stress.

\section{Acknowledgments}

This work was supported by the Brazilian Ministry of Health (Department of Science and Technology) and the Ministry of Science, Technology and Innovation (FINEP, Financiadora de Estudos e Projetos and CNPq, National Research Council), grants no. 0106 0010.00, $01060212.00,01060300.00,01060278.00,01060115.00$ and 0106 0071.00. LVC received a doctoral scholarship from Fundação de Amparo à Pesquisa do Estado de Minas Gerais (FAPEMIG) and was a CAPES - Brazilian Ministry of Education research fellow (grant no 99999.012455/2013-00) as a visiting scholar at the Harvard School of Public Health. SMB is a research fellow of the National Research Council (CNPq, grant no 300159/994). LG is a research fellow of the National Research Council (CNPq, grant no 312371/2013-6). The funders had no role in study design, data collection and analysis, decision to publish, or preparation of the manuscript.

\section{References}

Agha, G., Murabito, J.M., Lynch, J.W., Abrahamowicz, M., Harper, S.B., Loucks, E.B., 2011. Relation of socioeconomic position with ankle-brachial index. Am. J. Cardiol. 108 (11), 1651-1657.

Antigo, M.F., Machado, A.F., 2013. Mobilidade intrageracional de rendimentos no Brasil. Rev. Econ. Política 33 (1), 166-178.

Aquino, E.M., Barreto, S.M., Bensenor, I.M., Carvalho, M.S., Chor, D., Duncan, B.B., Lotufo, P.A., Mill, J.G., Molina, Mdel C., Mota, E.L., Passos, V.M., Schmidt, M.I., Szklo, M., 2012. ELSA-Brasil (Brazilian longitudinal study of adult health): objectives and design. Am. J. Epidemiol. 175 (4), 315-324.

Barford, A., Dorling, D., Davey Smith, G., Shaw, M., 2006. Life expectancy: women now on top everywhere. BMJ 332 (7545), 808.

Baron, R.M., Kenny, D.A., 1986. The moderator-mediator variable distinction in social psychological research: conceptual, strategic, and statistical considerations. J. Pers. Soc. Psychol. 51 (6), 1173-1182.

Barros, M.B.A., Francisco, P.M.S.B., Zanchetta, L.M., César, C.L.G., 2011. Trends in social and demographic inequalities in the prevalence of chronic diseases in Brazil. PNAD: 2003-2008. Ciência Saúde Coletiva 16 (9), 3755-3768.

Bassanesi, S.L., Azambuja, M.I., Achutti, A., 2008. Premature mortality due to cardiovascular disease and social inequalities in Porto Alegre: from evidence to action. Arq. Bras. Cardiol. 90 (6), 370-379.

Ben-Shlomo, Y., Kuh, D., 2002. A life course approach to chronic disease epidemiology: conceptual models, empirical challenges and interdisciplinary perspectives. Int. J. Epidemiol. 31 (2), 285-293.

Camelo, L.V., Giatti, L., Neves, J.A., Lotufo, P.A., Benseñor, I.M., Chor, D., Griep, R.H., da Fonseca Mde, J., Vidigal, P.G., Kawachi, I., Schmidt, M.I., Barreto, S.M., 2014. Life course socioeconomic position and C-reactive protein: mediating role of healthrisk behaviors and metabolic alterations. The Brazilian longitudinal study of adult health (ELSA-Brasil). PLoS One 9 (10), e108426.

Carson, A.P., Rose, K.M., Catellier, D.J., Kaufman, J.S., Wyatt, S.B., Diez-Roux, A.V., Heiss, G., 2007. Cumulative socioeconomic status across the life course and subclinical atherosclerosis. Ann. Epidemiol. 17 (4), 296-303.

Cohen, S., Janicki-Deverts, D., Chen, E., Matthews, K.A., 2010. Childhood socioeconomic status and adult health. Ann. N. Y. Acad. Sci. 1186, 37-55.

Danese, A., McEwen, B.S., 2013. Adverse childhood experiences, allostasis, allostatic load, and age-related disease. Physiol. Behav. 106 (1), 29-39.

El Khoudary, S.R., Wildman, R.P., Matthews, K., Thurston, R.C., Bromberger, J.T., Sutton-Tyrrell, K., 2013. Progression rates of carotid intima-media thickness and adventitial diameter during the menopausal transition. Menopause 20 (1) 8-14.

Ferrario, M.M., Veronesi, G., Chambless, L.E., Sega, R., Fornari, C., Bonzini, M. Cesana, G., 2011. The contribution of major risk factors and job strain to occupational class differences in coronary heartdisease incidence: the MONICA Brianza and PAMELA population based cohorts. Occup. Environ. Med. 68 (10), 717-722.

Galobardes, B., Lynch, J., Smith, G.D., 2007. Measuring socioeconomic position in health research. Br. Med. Bull. 81-82, 21-37.

Harper, S., Lynch, J., Smith, G.D., 2011. Social determinants and the decline of cardiovascular diseases: understanding the links. Annu. Rev. Public. Health 32, 39-69.

Huisman, M., Van Lenthe, F., Avendano, M., Mackenbach, J., 2008. The contribution of job characteristics to socioeconomic inequalities in incidence of myocardia infarction. Soc. Sci. Med. 66 (11), 2240-2252.

Instituto Brasileiro de Geografia e Estatística - IBGE, 2012. Pesquisa Nacional por Amostra de Domicílios 2012. Síntese de indicadores. Instituto Brasileiro de Geografia e Estatística, Rio de Janeiro, RJ.

Ishitani, L.H., Franco, G.C., Perpétuo, I.H.O., França, E., 2006. Socioeconomic inequalities and premature mortality due to cardiovascular diseases in Brazil. Rev. Saúde Pública 40 (4), 684-691.

Karasek, R.A., 1979. Job demand, job decision latitude, and mental strain: Implications for job redesign. Adm. Sci. Q. 24 (2), 285-308.

Kiggundu, M.N., 2012. Anti-poverty and progressive social change in Brazil: lessons for other emerging economies. Int. Rev. Adm. Sci. 78 (4), 733-756.

Kivimäki, M., Gimeno, D., Ferrie, J.E., Batty, G.D., Oksanen, T., Jokela, M., Virtanen, M. Salo, P., Akbaraly, T.N., Elovainio, M., Pentti, J., Vahtera, J., 2009. Socioeconomic position, psychosocial work environment and cerebrovascular disease among women: the finnish public sector study. Int. J. Epidemiol. 38 (5), 1265-1271.

Kivimäki, M., Lawlor, D.A., Juonala, M., Smith, G.D., Elovainio, M., KeltikangasJärvinen, L., et al., 2005. Lifecourse socioeconomic position, C-reactive protein, and carotid intima-media thickness in young adults: the cardiovascular risk in young finns study. Arterioscler. Thromb. Vasc. Biol. 25 (10), 2197-2202.

Kuh, D., Ben-Shlomo, Y., Lynch, J., Hallqvist, J., Power, C., 2003. Life course epidemiology. J. Epidemiol. Community. Health 57 (10), 778-783.

Kuh, D., Power, C., Blane, D., Bartley, M., 2004. Socioeconomic pathways between childhood and adult health. In: Kuh, D., Ben-Shlomo, Y. (Eds.), A Life Course Approach to Chronic Disease Epidemiology. Oxford University Press, Oxford UK, pp. 371-395.

Kuper, H., Adami, H.O., Theorell, T., Weiderpass, E., 2007. The socioeconomic gradient in the incidence of stroke: a prospective study in middle-aged women in Sweden. Stroke 38 (1), 27-33.

Kuper, H., Adami, H.O., Theorell, T., Weiderpass, E., 2006. Psychosocial determinants of coronary heart disease in middle-aged women: a prospective study in Sweden. Am. J. Epidemiol. 164 (4), 349-357.

Lamont, D., Parker, L., White, M., Unwin, N., Bennett, S.M., Cohen, M., et al., 2000. Risk of cardiovascular disease measured by carotid intima-media thickness at age 49-51: lifecourse study. BMJ 320, 273-278.

Lemelin, E.T., Diez Roux, A.V., Franklin, T.G., Carnethon, M., Lutsey, P.L., Ni, H., O'Meara, E., Shrager, S., 2009. Life-course socioeconomic positions and subclinical atherosclerosis in the multi-ethnic study of atherosclerosis. Soc. Sci. Med. 68 (3), 444-451.

Lorenz, M.W., Markus, H.S., Bots, M.L., Rosvall, M., Sitzer, M., 2007. Prediction of clinical cardiovascular events with carotid intima-media thickness: a systematic review and meta-analysis. Circulation 115 (4), 459-467.

Lotufo, P.A., Fernandes, T.G., Bando, D.H., Alencar, A.P., Benseñor, I.M., 2013. Income and heart disease mortality trends in Sao Paulo, Brazil, 1996 to 2010. Int. J. Cardiol. 167 (6), 2820-2833.

Loucks, E.B., Pilote, L., Lynch, J.W., Richard, H., Almeida, N.D., Benjamin, E.J., Murabito, J.M., 2010. Life course socioeconomic position is associated with inflammatory markers: the Framingham offspring study. Soc. Sci. Med. 71 (1), 187-195.

Lynch, J., Smith, G.D., 2005. A life course approach to chronic disease epidemiology. Annu. Rev. Public Health 26, 1-35.

Marmot, M., Bosma, H., Hemingway, H., Brunner, E., Stansfeld, S., 1997. Contribution of job control and other risk factors to social variations in coronary heart 
disease incidence. Lancet 350 (9073), 235-239.

McEwen, B.S., 2012. Brain on stress: how the social environment gets under the skin. Proc. Natl. Acad. Sci. U.S.A, 16109 (Suppl. 2), 17180-17185.

Miller, G.E., Chen, E., Parker, K.J., 2011. Psychological stress in childhood and susceptibility to the chronic diseases of aging: moving toward a model of behavioral and biological mechanisms. Psychol. Bull. 137 (6), 959-997.

Mishra, G.D., Cooper, R., Tom, S.E., Kuh, D., 2009. Early life circumstances and their impact on menarche and menopause. Womens Health (LondEngl) 5 (2), 175-190.

Rosvall, M., Ostergren, P.O., Hedblad, B., Isacsson, S.O., Janzon, L., Berglund, G., 2002. Life-course perspective on socioeconomic differences in carotid atherosclerosis. Arterioscler. Thromb. Vasc. Biol. 22, 1704-1711.

Santos, I.S., Bittencourt, M.S., Oliveira, I.R., Souza, A.G., Meireles, D.P., Rundek, T., et al.Lotufo, P.A., 2014. Carotid intima-media thickness value distributions in the Brazilian longitudinal study of adult health (ELSA-Brasil). Atherosclerosis 237 (1), 227-235.

Stary, H.C., 2000. Lipid and macrophage accumulations in arteries of children and the development of atherosclerosis. Am. J. Clin. Nutr. 72, 1297S-1306S.

Stringhini, S., Dugravot, A., Kivimaki, M., Shipley, M., Zins, M., Goldberg, M.
Ferrie, J.E., Singh-Manoux, A., 2011. Do different measures of early life socioeconomic circumstances predict adult mortality? Evidence from the British Whitehall II and French GAZEL studies. J. Epidemiol. Commun. Health 65 (12), 1097-1103.

Toivanen, S., Hemström, O., 2006. Income differences in cardiovascular disease: is the contribution from work similar in prevalence versus mortality outcomes? Int. J. Behav. Med. 13, 89-100.

VanderWeele, T.J., Robins, J.M., 2007. Directed acyclic graphs, sufficient causes, and the properties of conditioning on a common effect. Am. J. Epidemiol. 166 (9), 1096-1104.

Virtanen, S.V., Notkola, V., 2002. Socioeconomic inequalities in cardiovascular mortality and the role of work: a register study of finnish men. Int. J. Epidemiol. 31, 614-621.

Wamala, S.P., Mittleman, M.A., Horsten, M., Schenck-Gustafsson, K., Orth-Gomér, K. 2000. Job stress andthe occupational gradient in coronary heart disease risk in women. Stock. Female Coron. Risk Study. Soc. Sci. Med. 51 (4), 481-489.

White, I.R., Royston, P., Wood, A.M., 2011. Multiple imputation using chained equations: Issues and guidance for practice. Stat. Med. 30 (4), 377-399. 